\title{
Interaction of Phencyclidine with Voltage-Dependent Potassium Channels in Cultured Rat Hippocampal Neurons: Comparison with Block of the NMDA Receptor-lonophore Complex
}

\author{
J. M. H. ffrench-Mullen ${ }^{1}$ and M. A. Rogawski ${ }^{2}$ \\ 'Laboratory of Neurophysiology and 'Medical Neurology Branch, National Institute of Neurological Disorders and Stroke, \\ National Institutes of Health, Bethesda, Maryland 20892
}

Whole-cell voltage-clamp recording techniques were used to investigate the blockade of voltage-dependent $\mathrm{K}^{+}$channels by phencyclidine (PCP) in cultured rat hippocampal neurons. All recordings were carried out in the presence of tetrodotoxin $(1-2 \mu \mathrm{M})$ to eliminate $\mathrm{Na}^{+}$currents. Step depolarization from a holding potential of $-40 \mathrm{mV}$ activated a slowly rising, minimally inactivating $\mathrm{K}^{+}$current $\left(l_{\mathrm{K}}\right)$. PCP $(0.5-1000 \mu \mathrm{M})$ caused a reduction in the maximum conductance of $I_{K}\left[1 C_{50}(+30 \mathrm{mV}), 22 \mu \mathrm{M}\right]$ without altering its voltage dependency. The PCP block of $l_{k}$ diminished at depolarized potentials. Analysis according to the scheme of Woodhull (1973) suggested that block occurs via binding to an acceptor site (presumably within the channel pore) that senses $\mathbf{4 0 - 5 0 \%}$ of the transmembrane electrostatic field. PCP had no effect on the kinetic properties of $I_{K}$ and the block failed to show use dependency, suggesting that PCP may bind to the $I_{k}$ channel via a hydrophobic mechanism not requiring open channels. For comparison, we also investigated the effect of PCP on the transient $K^{+}$current, $I_{A}$, activated by step depolarization following a $200 \mathrm{msec}$ prepulse to -90 $\mathrm{mV}$ (20 mM tetraethylammonium was present in the bathing solution to reduce $I_{k}$ ). In contrast to the potent blocking action of PCP on $I_{K}$, the drug only affected $I_{A}$ at high concentrations $\left[\mathrm{IC}_{50}(+30 \mathrm{mV}), 224 \mu \mathrm{M}\right]$. At concentrations causing substantial block (300-500 $\mu \mathrm{M}$ ), PCP produced an acceleration in the $I_{A}$ inactivation rate, and, for brief (5-6 msec) depolarizing steps, the suppression of $I_{A}$ was use dependent. These observations suggest that PCP block of $I_{A}$ requires open channels. PCP reduced inward current responses induced by the excitatory amino acid agonist N-methyl-D-aspartate (NMDA) at substantially lower concentrations than those required for its effects on $\mathrm{K}^{+}$channels $\left[\mathrm{IC}_{50}(-60 \mathrm{mV}), 0.45 \mu \mathrm{M}\right]$. The PCP-like dioxadrol stereoisomer dexoxadrol $(10 \mu \mathrm{M})$ blocked NMDA-evoked inward current responses, while its behaviorally inactive enantiomer levoxadrol did not. Dexoxadrol and levoxadrol also blocked $l_{k}$ in a stereoselective fashion $\left(\mathrm{IC}_{50}\right.$ 's, 73 and $260 \mu \mathrm{M}$, respectively), whereas the sigma ligands $(+)$ - and (-)-SKF 10,047 and (+)-3-[3-hydroxyphenyl]- $\mathrm{N}$-(1-propyl)piperidine $[(+)-3$ -

\footnotetext{
Received Jan. 24, 1989; revised May 31, 1989; accepted May 31, 1989.

We thank Dr. J. L. Barker for providing laboratory facilities. J.M.H.ff.-M. was a NIH Resident Research Associate of the National Research Council.

Correspondence should be addressed to Michael A. Rogawski, M.D., Ph.D., Medical Neurology Branch, NINDS, NIH, Bldg. 10, Rm. 5N-248, Bethesda, MD 20892.

Copyright (C) 1989 Society for Neuroscience $0270-6474 / 89 / 114051-11 \$ 02.00 / 0$
}

PPP] had little effect on the current (IC ${ }_{50}$ 's, $\left.>300-500 \mu \mathrm{M}\right)$. We conclude that PCP causes a selective, voltage-dependent block of $I_{\mathrm{K}}$ in hippocampal neurons via a PCP. and not a sigma-type acceptor site. The atfinity of PCP for its acceptor site on $l_{k}$ channels (corrected for the voltage dependence) is 13 times lower than its affinity for NMDA-receptorassociated channels. Therefore, at low doses, the behavioral effects of the drug are more likely to result from an interaction with NMDA receptor channels than voltage-dependent $\mathrm{K}^{+}$channels.

The dissociative anesthetic phencyclidine (PCP) blocks a wide variety of ligand- and voltage-gated ion channels in neural and muscle membranes (Albuquerque et al., 1981; Tourneur et al., 1982; Hadley and Hume, 1986; Lacey and Henderson, 1986). In particular, studies using $\mathrm{Rb}^{+}$flux measurements (Bartschat and Blaustein, 1986) and voltage-clamp techniques (ffrenchMullen et al., 1988) have demonstrated that the drug produces a selective depression of current flow through sustained (minimally inactivating) voltage-dependent $\mathrm{K}^{+}$channels in mammalian brain (often referred to as "delayed rectifier" channels). During the past 2 decades, a conceptual framework for the mechanistic analysis of channel block has developed as a result of extensive studies on the interaction of reversible channel-blocking agents with voltage-dependent $\mathrm{Na}^{+}$channels and $\mathrm{ACh}$-gated cation channels (see Woodhull, 1973; Adams, 1976; Yeh and Narahashi, 1977; Armstrong and Croop, 1982). These studies have led to the conclusion that many channel-blocking agents may act by binding specifically to an acceptor site within the channel pore and that this causes a temporary steric barrier to ion transit through the channel. Recently, it has been suggested that PCP may block nicotinic ACh receptor- (Oswald et al., 1984; Aguayo and Albuquerque, 1986) and $N$-methyl-D-aspartate (NMDA) receptor-coupled cation channels by such a mechanism (Honey et al., 1985). We have provided preliminary qualitative data in support of such a mechanism underlying the PCP block of voltage-dependent $\mathrm{K}^{+}$channels (ffrench-Mullen et al., 1988; Rogawski et al., 1988).

In the present report, we describe more detailed experiments on the interaction between PCP and voltage-dependent $\mathrm{K}^{+}$channels in cultured hippocampal neurons. We provide data on the specificity and affinity of the PCP acceptor site, on the voltage dependency of the block, and the effects of PCP on the kinetic properties of the currents. For comparison, we also furnish data on the affinity of PCP for NMDA receptor channels in the same cells. Our results lead to the conclusion that PCP blocks $I_{\mathrm{K}}$ 
channels by binding to a stereoselective acceptor site that is likely to be within the channel pore. However, the affinity of PCP for its acceptor site on the $I_{\mathrm{K}}$ channel is an order of magnitude lower than its affinity for the NMDA receptor channel. In addition, the pharmacological specificity of the $I_{\mathrm{K}}$ binding site may differ from that of the behaviorally relevant PCP receptor. Therefore, we conclude that at low doses the behavioral effects of PCP are more likely to result from an interaction of the drug with excitatory amino acid-mediated neurotransmission than with voltage-dependent $\mathrm{K}^{+}$channels.

\section{Materials and Methods}

Cell culture. Neurons from 17- to 19-d-old Sprague-Dawley rat embryos were grown in dissociated culture according to methods described by Segal (1983). The cultures were prepared in modified Minimal Eagle's Medium supplemented with $10 \%$ horse serum, $10 \%$ fetal calf serum, and $1 \%$ glutamine (GIBCO, Grand Island, NY) and were incubated at $37^{\circ} \mathrm{C}$ in a humidified atmosphere containing $10 \% \mathrm{CO}_{2}$. Fresh medium was added every $4 \mathrm{~d}$. Cells were used for electrophysiological recording 6-12 d after plating.

Whole-cell recording. All recordings were made at room temperature $\left(19-25^{\circ} \mathrm{C}\right)$ on the stage of an inverted phase-contrast microscope (Nikon Diaphot). Prior to each experiment, the serum containing growth medium was replaced with recording medium containing (in mM): $\mathrm{NaCl}$, $140 ; \mathrm{KCl}, 5 ; \mathrm{CaCl}_{2}, 1.5 ; \mathrm{MgCl}_{2}, 1 ; 4$-(2-hydroxyethyl)-1-piperazine-ethanesulfonic acid (HEPES), 5; D-glucose, 6 . In some experiments, the following tetraethylammonium (TEA)-containing solution was used: $\mathrm{NaCl}, 130 ; \mathrm{KCl}, 5 ; \mathrm{CaCl}_{2}, 1.5 ; \mathrm{MgCl}_{2}, 1 ; \mathrm{CdCl}_{2}, 0.05 ; \mathrm{TEA}-\mathrm{Cl}, 20$; HEPES, 5; D-glucose, 6 . The solutions were adjusted to $\mathrm{pH} 7.4$ with $\mathrm{NaOH}$ and to an osmolality of $325 \mathrm{mOsm} / \mathrm{kg} \mathrm{H} \mathrm{H}_{2} \mathrm{O}$ with sucrose and were filtered through a $0.22 \mu \mathrm{m}$ membrane filter (Millipore Corp., Bedford, MA) immediately before use. Tetrodotoxin (1-2 $\mu \mathrm{M})$ was always added to the recording solutions. For recording NMDA-activated inward currents, $\mathrm{MgCl}_{2}$ was omitted from the extracellular medium.

Patch electrodes were prepared from $1.5 \mathrm{~mm}$ O.D. filament fused, borosilicate glass capillaries (Kwik-Fil TW150F, WPI Instruments, New Haven, CT) using a BB-CH programmable horizontal puller (Mecanex, Geneva). The electrodes were pulled in 2 stages, and, without further preparation, were filled with intracellular solution of the following composition (in $\mathrm{mM}$ ): $\mathrm{K}$-gluconate, $145 ; \mathrm{CaCl}_{2}, 0.1 ; \mathrm{MgCl}_{2}, 2$; ethylene glycol $b i s\left(\beta\right.$-aminoethyl ether)- $N, N, N, N^{\prime}$-tetraacetic acid (EGTA), 1.1 or $\mathrm{K}$-bis( $O$-aminophenoxy)ethane- $N, N, N^{\prime}, N^{\prime}$-tetraacetic acid (BAPTA), 5; HEPES, 5 . In some experiments $\mathrm{CaCl}_{2}$ was omitted. The pipette solution was adjusted to $\mathrm{pH} 7.2$ with $\mathrm{KOH}$ and to an osmolality of $315 \mathrm{mOsm} /$ $\mathrm{kg} \mathrm{H}_{2} \mathrm{O}$ with sucrose. Pipette-to-bath resistances prior to seal formation were typically 3-7 M 2 . Seal resistances were $>10 \mathrm{G} \Omega$. Liquid junction potentials between the electrode solution and the bath were minimized by placement of the reference electrode in a compartment filled with the pipette solution that was electrically connected to the tissue culture dish by an agar bridge.

Whole-cell currents were recorded with an Axopatch 1A patch-clamp amplifier (Axon Instruments, Burlingame, CA). After seal formation and prior to establishing a whole-cell recording, electrode capacitance was neutralized by using the capacitance compensation circuitry of the Axopatch. In the whole-cell mode, the Axopatch was further adjusted to correct for $80-85 \%$ of the series resistance. Voltage-step families were applied at a rate of $0.3-0.5 \mathrm{~Hz}$.

Data acquisition and analysis. Voltages corresponding to the current signals were conditioned with the low-pass filter on the Axopatch set at a cutoff frequency of $10 \mathrm{kHz}$. The signals were digitized using a 12 bit $( \pm 10 \mathrm{~V})$ analog-to-digital converter at a rate of $500 \mu \mathrm{sec} /$ point and were stored on the Winchester disk of a minicomputer for later analysis with an automatic measuring program. Raw current traces in most cases are displayed without leak subtraction; however, all derived values were determined following linear leak subtraction accomplished by extrapolating the best-fit straight line to the current values obtained with voltage steps to between -80 and $-50 \mathrm{mV}$. In the records shown in Figure 8, capacitance artifacts and leakage currents were digitally subtracted by addition to the raw data of an average and appropriately scaled current response to a $10 \mathrm{mV}$ hyperpolarizing voltage step.

Except as noted, percent blockade was determined according to the formula $100 \times\left(1-I_{\text {drug }} / I_{\text {control }}\right)$, where $I_{\text {control }}$ is the current amplitude before drug application and $I_{\text {drug }}$ is the current amplitude obtained ap- proximately $2 \mathrm{~min}$ after the onset of the drug superfusion. For all doseresponse data, $\mathrm{K}^{+}$current blockade was determined at $+30 \mathrm{mV}$ and NMDA-activated inward current blockade was determined at $-60 \mathrm{mV}$. Data are expressed as means \pm SEM. " $95 \%$ C.L." refers to the $95 \%$ confidence limits of the derived value.

Fitting of dose-response data was carried out with the program ALLFIT as described by De Lean et al. (1978). Other nonlinear curve fitting was performed with an interactive mathematical modeling system (MLAB; Division of Computer Research and Technology, NIH) using a tuned version of the Marquardt-Levenberg iterative least-squares algorithm. Linear least-squares curve fitting and final plotting were performed on a microcomputer using the Grapher software package (Golden Software, Golden, $\mathrm{CO}$ ). The Lineweaver-Burke analysis used for the determination of dissociation constants was carried out with the microcomputer programs accompanying Tallarida and Murray (1987). Statistical analyses were performed with Systat Version 4.0 (Systat, Inc., Evanston, IL).

Drug application. Drugs were dissolved in bathing medium and were applied by pressure ejection (typically $0.3-1$ psi) from blunt glass micropipettes (tip diameter, $1-2 \mu \mathrm{m}$ ) positioned close to the cell membrane. It has previously been demonstrated that this method delivers a concentration of drug at the cell surface that is close to that in the pressure pipette (Choi and Fishbach, 1981). Therefore, drug concentrations reported are the uncorrected concentrations in the pressure pipette. A few experiments in which drugs were applied by bath perfusion gave comparable results to those obtained with the pressure-ejection technique. Except as noted, testing of the $\mathrm{K}^{+}$currents for block was begun 2-3 min following onset of the drug application. NMDA was applied by brief (100-300 msec) pressure pulses delivered to the cell at 30 sec intervals to avoid desensitization. Fractional block was determined after several NMDA applications when the reduction in peak current amplitude had attained a steady-state level.

Materials. PCP [1-(1-phenylcyclohexyl)piperidine $\mathrm{HCl}]$ and $(+)-$ and $(-)$-SKF 10,047 [(+)- and (-)- $N$-allyl- $N$-normetazocine $\mathrm{HCl}]$ were obtained from the National Institute on Drug Abuse, Research Technology Branch, Research Triangle Park, NC. Dexoxadrol $\mathrm{HCl}$ and levoxadrol $\mathrm{HCl}$ were generous gifts of Drs. K. C. Rice, A. E. Jacobson, and A. Thurkauf, NIDDK. (+)-3-PPP [R(+)-3-(2-hydroxyphenyl)- $N$-propylpiperidine $\mathrm{HCl}$ ] was from Research Biochemicals, Inc. (Natick, MA). All chemicals whose sources are not specified were obtained from Sigma Chemical Co. (St. Louis, MO).

\section{Results}

The data presented in this report represent the results of wholecell voltage-clamp recordings from 316 cultured rat hippocampal neurons.

\section{$P C P$ blocks $\mathrm{I}_{K}$ with greater potency than $\mathrm{I}_{A}$}

Step depolarization of hippocampal neurons for $200 \mathrm{msec}$ from a holding potential of $-40 \mathrm{mV}$ to potentials between -30 and $+40 \mathrm{mV}$ resulted in the activation of a voltage-dependent outward current that rose to a plateau within $20-30 \mathrm{msec}$ and showed no or minimal $(<10 \%)$ inactivation during the remainder of the voltage command step (Fig. 1A, left). This sustained outward current $\left(I_{\mathrm{K}}\right)$ has previously been shown to be primarily due to activation of TEA-sensitive, voltage- but not $\mathrm{Ca}^{2+}$-dependent $\mathrm{K}^{+}$channels (Segal and Barker, 1984; ffrench-Mullen et al., 1988). At a holding potential of $-40 \mathrm{mV}$, the transient $\mathrm{K}^{+}$current, $I_{\mathrm{A}}$, in cultured hippocampal neurons is inactivated and does not contribute to the total outward current (Segal et al., 1984). Upon repolarization, $I_{\mathrm{K}}$ deactivates within $50 \mathrm{msec}$. Analysis of tail currents in 5 cells showed a reversal potential of $-60.2 \pm 0.4 \mathrm{mV}$ (range, -58 to $-65 \mathrm{mV}$ ), and this is taken to be the equilibrium potential for $\mathrm{K}^{+}$currents under these recording conditions. The deviation of the tail current reversal potential from the calculated Nernst potential is likely due to $\mathrm{K}^{+}$accumulation near the external membrane face during the prolonged depolarizing steps, as well as errors caused by the liquid-junction potential generated at the bathing medium-pi- 
pette solution interface and the Donnan potential at the electrode tip.

Superfusion with PCP caused a dose-dependent suppression of $I_{\mathrm{K}}$ (Figs. 1, right, and 3). At low concentrations $(\leq 100 \mu \mathrm{M})$, 2-3 min was required to achieve a plateau in the blocking effect, whereas with higher concentrations a maximal response to the drug was obtained within $1 \mathrm{~min}$. Figure $1 A$ illustrates the effect of $20 \mu \mathrm{M}$ PCP on $I_{\mathrm{K}}$ elicited at several step potentials $(-10,0$, $+10,+20,+30 \mathrm{mV}$ ) and Figure $1 B$ (bottom) plots the leaksubtracted conductance at the end of the $200 \mathrm{msec}$ step as a function of the step potential under control conditions and in the presence of PCP. PCP caused a reduction in the net $I_{\mathrm{K}}$ conductance without altering the voltage dependency of the current as determined by the $V_{1 / 2}$ values of the best-fit Boltzman curves to the data (control: $8.9 \mathrm{mV}$; PCP: $9.1 \mathrm{mV}$; see caption to Fig. 1). Figure $3 A$ shows the percent block of $I_{\mathrm{K}}$ for various concentrations of PCP from 0.5 to $1000 \mu \mathrm{M}$. Assuming a reversible bimolecular binding reaction between PCP and an acceptor site on the $I_{\mathrm{K}}$ channel and, furthermore, that occupancy of the acceptor site results in channel block, the fractional block of the channel, $B$, can be described by a Langmuir adsorption isotherm:

$$
B=1 /\left(1+K_{D} /[\mathrm{PCP}]\right)
$$

where $K_{D}$ is the equilibrium dissociation constant of the binding reaction. This equation was modified as follows:

$$
B=B_{\max } /\left\{1+\left(\mathrm{IC}_{50} /[\mathrm{PCP}]\right)^{n}\right\}
$$

where $B_{\max }$ is a parameter $\leq 1$ that accounts for the possibility that a fraction of the measured outward current represents contamination by drug resistant channels, $\mathrm{IC}_{50}$ is the concentration of drug that produces $B_{\max } / 2$ block, and $n$ is an empirical parameter that determines the steepness of the dose-effect curve and considers the potential existence of heterogeneous binding sites. Only under conditions where $n=1$, does the $\mathrm{IC}_{50}$ provide a true estimate of $K_{D}$. As illustrated in Figure $3 A$, the dose-effect curve for blockade of $I_{\mathrm{K}}$ is reasonably well fit by a curve defined by Eq. ( $\left.1^{\prime}\right)$ with $B_{\max }=0.84 \pm 0.10, \mathrm{IC}_{50}=22 \pm 11$, and $n=$ $0.71 \pm 0.20$. The fact that $n<1$ suggests the existence of 2 binding sites. Transforming Eq. (1) by taking the reciprocal of both sides results in a linear form in which $K_{D}$ is the slope of the line obtained by plotting $1 / B$ against $1 /[\mathrm{PCP}]$. Figure $3 B$ shows the transformed dose-response data. The data are well fit by a straight line for PCP concentrations $>10 \mu \mathrm{M}$ giving a $K_{D}$ at $+30 \mathrm{mV}$ of $25.7 \pm 1.0 \mu \mathrm{M}(95 \%$ C.L.: 22.9-28.5). However, as is apparent from the double-reciprocal plot, the points with very low concentrations of PCP $(\leq 1 \mu \mathrm{M})$ deviate from the line, suggesting the presence of an additional higher-affinity acceptor site with $K_{D} \sim 7 \mu \mathrm{M}$. This acceptor site produces a qualitatively minor contribution to the total outward current block produced by PCP and could reflect a second, high-affinity binding site on the $I_{\mathrm{K}}$ channel or the effect of PCP on a contaminating outward current species.

Conditioning hyperpolarization of hippocampal neurons to potentials more negative than $-50 \mathrm{mV}$ results in deinactivation of the A current $\left(I_{\mathrm{A}}\right)$, a rapidly activating and inactivating, TFAinsensitive $\mathrm{K}^{+}$current (Segal et al., 1984). We examined the effects of PCP on $I_{\mathrm{A}}$ by activating the current with a voltageclamp protocol consisting of a $200 \mathrm{msec}$ hyperpolarizing prepulse to $-90 \mathrm{mV}$, followed by a $200 \mathrm{msec}$ depolarizing step to various potentials between -50 and $+30 \mathrm{mV}$. During the $2-3$ sec rest period between the hyperpolarizing-depolarizing se-
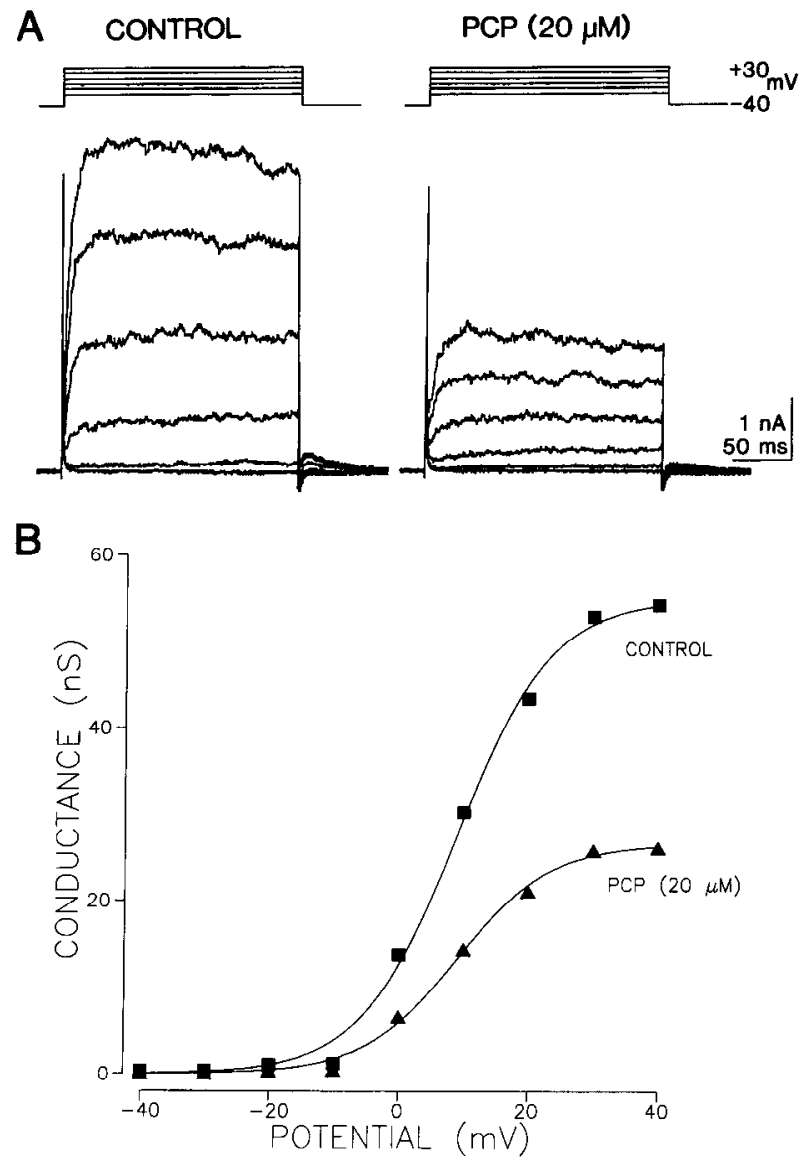

Figure 1. PCP-induced depression of the sustained voltage-dependent $\mathrm{K}^{+}$current $\left(I_{\mathrm{K}}\right) . A, I_{\mathrm{K}}$ was evoked with a family of $200 \mathrm{msec}$ depolarizing steps applied before (left) and during (right) superfusion with $20 \mu \mathrm{M}$ PCP. $B$, The $I_{\mathrm{K}}$ conductance for each step (plotted on lower graph) was determined from the data shown in $A$ according to the relationship $G$ $=I /\left(V-V_{r}\right)$, where $I$ is the leak subtracted current at the end of the $200 \mathrm{msec}$ voltage step, $V$ is the step potential, and $V_{r}$ is the reversal potential for $\mathrm{K}^{+}$currents as determined by tail current analysis (see text). The smooth curves were fitted to the data according to a Boltzman equation of the form $G=G_{\max }\left\{1+\exp \left[\left(V_{1 / 2}-V\right) / A\right]\right\}^{-1}$, where the parameter values $( \pm \mathrm{SEM})$ before and during the drug treatment, respectively, were: $G_{\max }(\mathrm{pS})=54.7 \pm 1.4,26.5 \pm 0.7 ; V_{1_{2}}(\mathrm{mV})=8.9 \pm$ $0.8,9.1 \pm 0.8 ; A=7.3 \pm 0.6,7.2 \pm 0.6$.

quences, the cells were held at $-60 \mathrm{mV}$. TEA (20 mM) was present in the bathing medium to reduce $I_{\mathrm{K}}$ and allow $I_{\mathrm{A}}$ to be studied in relative isolation. In contrast to the potent blocking action of PCP on $I_{\mathrm{K}}$ at doses in the low micromolar range, the drug failed to affect $I_{\mathrm{A}}$ at doses $\leq 20 \mu \mathrm{M}$ and caused only minimal blockade at $50 \mu \mathrm{M}$ (Fig. $2 A$ ). Higher doses did cause a dosedependent reduction in $I_{\mathrm{A}}$ (Fig. $2 B$ ) with an $\mathrm{IC}_{50}$ at $+30 \mathrm{mV}$ of $224 \pm 32 \mu \mathrm{M}$ (Fig. $3 A$ ). As was the case for $I_{\mathrm{K}}$, there was no change in the voltage dependency for activation of $I_{\mathrm{A}}$ in the presence of PCP (see caption to Fig. 2).

\section{PCP block of $\mathrm{I}_{\mathrm{K}}$ is voltage dependent}

The degree to which PCP blocks $I_{\mathrm{K}}$ diminishes at more positive membrane potentials. Voltage dependency of block data from experiments with 7 cells exposed to $20 \mu \mathrm{M}$ are summarized in Figure 4. The upper panel shows the combined current-voltage relationship for $I_{\mathrm{K}}$ in these cells under control conditions and in the presence of PCP; the lower panel gives the percent block as a function of membrane potential. PCP is a charged molecule 
A
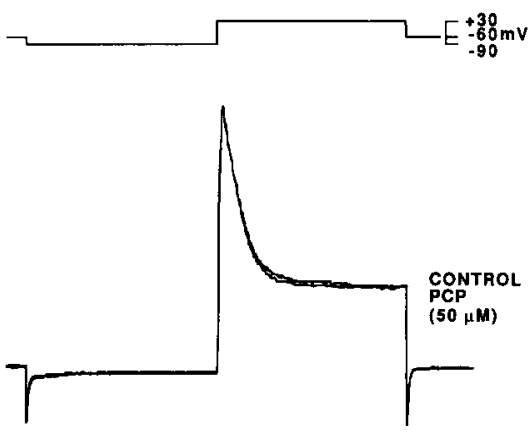

Figure 2. PCP-induced depression of the transient voltage-dependent $\mathrm{K}^{+}$current $\left(I_{\mathrm{A}}\right) . I_{\mathrm{A}}$ was evoked with a family of $200 \mathrm{msec}$ depolarizing steps applied after a $200 \mathrm{msec}$ conditioning prepulse to $-90 \mathrm{mV}$. Cells were held at $-60 \mathrm{mV}$ between steps. TEA $(20 \mathrm{~mm})$ was added to the bathing medium to reduce $I_{\mathrm{K}}$. Sample traces are shown for steps to $+30 \mathrm{mV}$ before and during superfusion with $\operatorname{PCP}(A, 50 \mathrm{mM} ; B, 500 \mu \mathrm{M})$. Graphs plot $I_{\mathrm{A}}$ conductance calculated according to the formula given in the caption to Figure 1, except that $I$ is taken to be the peak current minus the current at the end of the $200 \mathrm{msec}$ step. Smooth curves were fit with the Boltzman equation. The parameter values are as follows $($ Control, $P C P)$ : $A, G_{\max }(\mathrm{pS})=16.3$ $\pm 0.2,15.5 \pm 0.2 ; V_{1,2}(\mathrm{mV})=-11.3$ $\pm 0.5,-13.0 \pm 0.6 ; A=8.5 \pm 0.5,8.9$ $\pm 0.5 ; B, G_{\max }=17.4 \pm 0.4,8.5 \pm 0.2$ $V_{1 / 2}=7.8 \pm 1.0,10.3 \pm 1.1 ; A=12.2$ $\pm 0.7,11.5 \pm 0.9$.

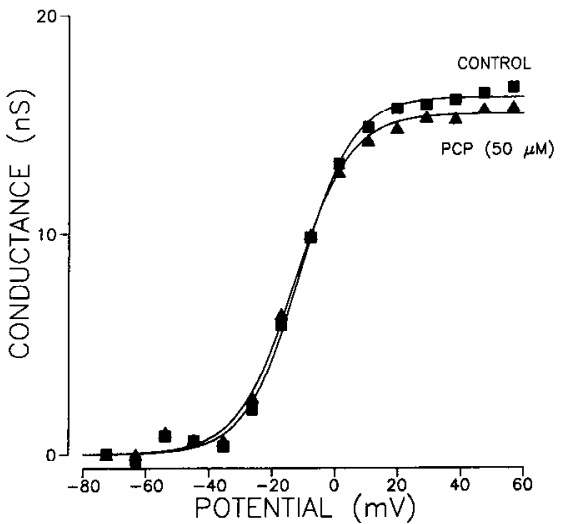

B
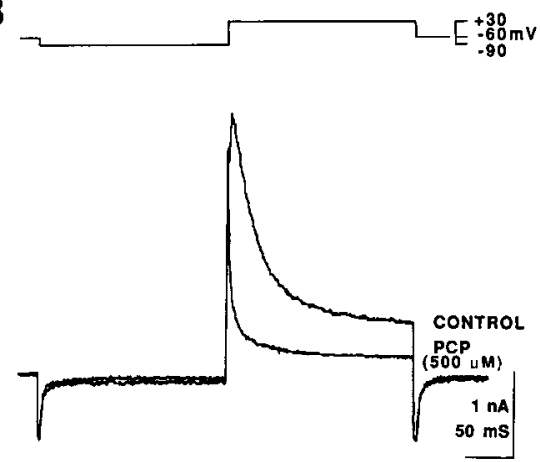

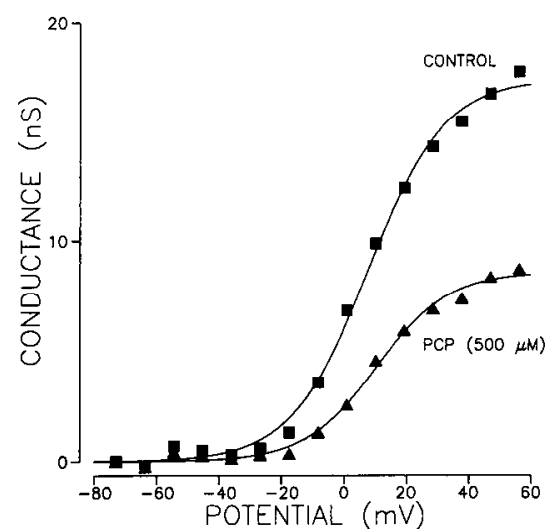

at physiological $\mathrm{pH}$ due to protonation of the piperidine ring nitrogen atom $\left(\mathrm{p} K_{a}, 9.4\right.$ at $25^{\circ} \mathrm{C}$; Maayani et al., 1983). Therefore, if the PCP blocking site is within the electric field of the membrane, at positive membrane potentials, electrostatic forces would tend to drive the PCP molecule from the acceptor site and decrease the degree of block. The voltage dependency of block was further analyzed according to the approach originally described by Woodhull (1973). In this model, the ratio of the net (leak-subtracted) currents in the absence and presence of $\mathrm{PCP}, I_{0}$ and $I_{\mathrm{PCP}}$, can be related to the transmembrane voltage, $V$, by the relationship

$$
I_{0} / I_{\mathrm{PCP}}=1+\left\{[\mathrm{PCP}] / K_{D}(0)\right\} \exp (-z F V \delta / R T),
$$

where $K_{D}(0)$ represents the dissociation constant of the PCPacceptor site complex at zero transmembrane potential, $\delta$ is the fractional voltage drop experienced at the acceptor site, and $z$, $F, R, T$ have their usual meanings. Equation (2) can be linearized by rearranging and taking the natural logarithms of both sides resulting in the following equation for a straight line:

$$
\ln \left(I_{0} / I_{\mathrm{PCP}}-1\right)=\ln \left\{[\mathrm{PCP}] / K_{D}(0)\right\}-(z \delta F / R T) \times V,
$$

in which $K_{D}(0)$ and $\delta$ can be determined from a plot of $\ln \left(I_{0}\right)$ $I_{\mathrm{PCP}}-1$ ) against $V$ (cf. Coronado and Miller, 1979; Blatz and Magleby, 1984; Wong and Adler, 1986; Smart, 1987). Data similar to that of Figure 4 expressed in this fashion are shown in Figure $5 A$, where linear least-squares fits give $K_{D}(0)$ of 19.4 $\mu \mathrm{M}$ and $\delta$ of 0.49 .

As an independent means of estimating $\delta$, we utilized the following expression for the voltage dependency of the binding constant (also taken from Woodhull, 1973):

$$
K_{D}(V)=K_{D}(0) \exp (\delta F V / R T) \text {. }
$$

Plots of fractional block against the logarithm of the PCP concentration (10-300 $\mu \mathrm{M} ; 5-8$ cells at each of 5 concentrations) were made at potentials of -30 to $+30 \mathrm{mV}$. The $\mathrm{IC}_{50}(V)$ values as determined from the best-fit lines to the data were used as estimates of $K_{D}(V)$ and are plotted in Figure $5 B$. The fraction of the voltage drop at the blocking site, $\delta$, determined by this method was 0.39 , which is reasonably close to the value obtained with the previous analysis. According to Eq. (4), the dissociation constant increases $e$-fold per $66 \mathrm{mV}$ increase in membrane potential. Correcting the $K_{D}(0)$ values determined in Figure $5 A$ with Eq. (4) to $+30 \mathrm{mV}$ gives a value for $K_{D}(+30)$ of $30.4 \mu \mathrm{M}$, which is similar to the value obtained by the titration method for the major blocking site described above (Fig. $3 B$ ).

\section{PCP alters the kinetic properties of $\mathrm{I}_{\mathrm{K}}$ and $\mathrm{I}_{\mathrm{A}}$ in different ways}

Following step depolarization, $I_{\mathrm{K}}$ reaches a plateau in about 20 msec. The activation of the current occurred in 2 exponential phases as illustrated in Figure $6 \mathrm{~A}$. Depite the reduction in peak current observed with PCP, the drug did not alter the time course of activation. In the experiment illustrated in Figure $6 A, I_{\mathrm{K}}$ was activated by a voltage step from -40 to $+30 \mathrm{mV}$. Superfusion with $20 \mu \mathrm{M}$ PCP caused a $42 \%$ reduction in the plateau current; however, as is apparent from the normalized current records shown in Figure $6 \mathrm{~A}$, there was no change in the activation kinetics. A similar lack of effect on the activation kinetics was observed with steps to less depolarized potentials $(0,+10$, and $+20 \mathrm{mV}$; 2 cells examined; data analysis not shown).

In some cells there was a minimal $(<5-10 \%)$ time-dependent decay of $I_{\mathrm{K}}$ during the $200 \mathrm{msec}$ voltage step, particularly at very depolarized potentials ( +20 to $+30 \mathrm{mV}$; cf. Fig. $1 A$, left). PCP caused no consistent increase in the decay rate, and, in 

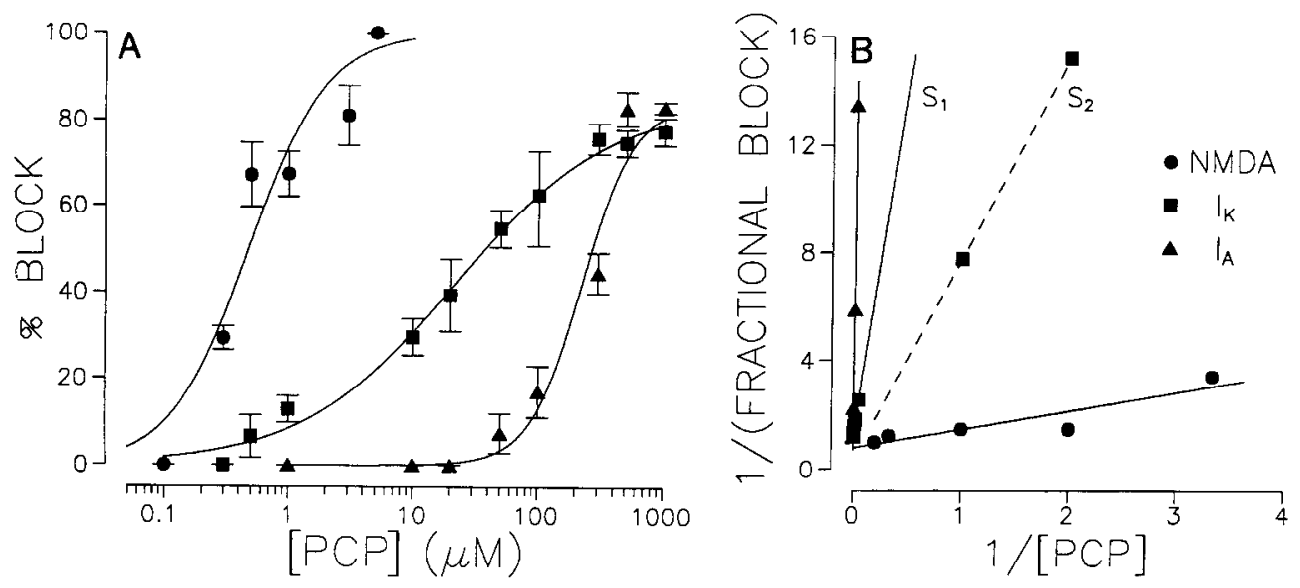

Figure 3. A, Dose-effect curves for PCP block of NMDA-evoked inward current responses $(\boldsymbol{\bullet}), I_{\mathrm{K}}(\boldsymbol{\square})$, and $I_{\mathrm{A}}(\mathbf{\Delta})$. NMDA-cvoked currents were recorded at $-60 \mathrm{mV}$, whereas $\mathrm{K}^{+}$currents were elicited with voltage steps to $+30 \mathrm{mV}$. Percent block was determined according to the formula given in Materials and Methods. Testing for block was carried out $2 \mathrm{~min}$ after the onset of the $\mathrm{PCP}$ ejection. Each point represents the mean \pm SEM of experiments on 4-8 cells. Smooth curves represent the best fits to the data according to Eq. (1') with parameters as given in the text. $B$, Double-reciprocol plots of the data shown in $A$ (except that fractional block was uscd). $S_{1}$ and $S_{2}$ represent 2 putative components of the $I_{\mathrm{K}}$ data. Some of the data were taken from ffrench-Mullen et al. (1988). fact, in most cases, the drug reduced the decay rate (cf. Fig. $9 \mathrm{~A}$ ). We observed little use-dependent block of $I_{\mathrm{K}}$. For example, in a cell exposed initially to $20 \mu \mathrm{M}$ PCP and pulsed continuously at $0.5 \mathrm{~Hz}$ from -40 to $+30 \mathrm{mV}$ to activate $I_{\mathrm{K}}$, there was a $33 \%$ block of the current at $3 \mathrm{~min}$ following onset of the drug perfusion. The PCP perfusion was then discontinued and the outward current was allowed to recover to its predrug amplitude. When PCP was again applied with the cell held continuously at $-40 \mathrm{mV}$ and tested with a single pulse only at $3 \mathrm{~min}$, the current was reduced by $30 \%$. A second cell was studied with $100 \mu \mathrm{M}$ PCP using the same protocol except that repetitive activation was performed first. The initial trial gave $57 \%$ block at $3 \mathrm{~min}$, while the second gave $54 \%$ block. Thus, we were unable to demonstrate significant use dependency for the PCP block of $I_{\mathrm{K}}$. This observation in conjunction with the failure of PCP to cause pseudo-inactivation of $I_{\mathrm{K}}$ demonstrates that the binding of PCP to its acceptor site in the $\mathrm{K}^{+}$channel occurs rapidly in comparison with the rate of channel activation or that the drug can bind to the blocking site while the channels are in their resting (closed) state.

$I_{\mathrm{A}}$ activates rapidly following depolarization (peak, 3-10 msec; +30 to $-10 \mathrm{mV}$ ) and inactivates in an exponential fashion with a time constant of 10-40 msec (Segal et al., 1984). While the time to peak of $I_{\mathrm{A}}$ occurs slightly earlier at more depolarized step potentials, the decay rate of the current is independent of potential. The speed with which $I_{\mathrm{A}}$ reaches a peak precluded a detailed analysis of the effects of PCP on the activation kinetics of the current. Nevertheless, it is apparent from the records shown in Figure $2 B$ that in the presence of concentrations of PCP which cause a substantial reduction in the current $(>300$ $\mu \mathrm{M})$, the peak occurred earlier than normal ( $<3 \mathrm{msec}$ ). In addition, PCP caused a marked speeding of the $I_{\mathrm{A}}$ decay rate. As illustrated in Figure $6 B$ (same cell as Fig. $2 B$ ), decay of $I_{\mathrm{A}}$ is normally well fit by a single exponential function. In the presence of PCP, however, inactivation occurs in 2 exponential phases. The initial phase is markedly faster than the control decay, whereas the late phase is slower. The apparent facilitation of A-current inactivation by PCP resembles the effects of various channel-blocking agents on voltage-dependent $\mathrm{Na}^{+}$channels (Yeh and Narahashi, 1977; Cahalan and Almers, 1979; Kirsch et al.,
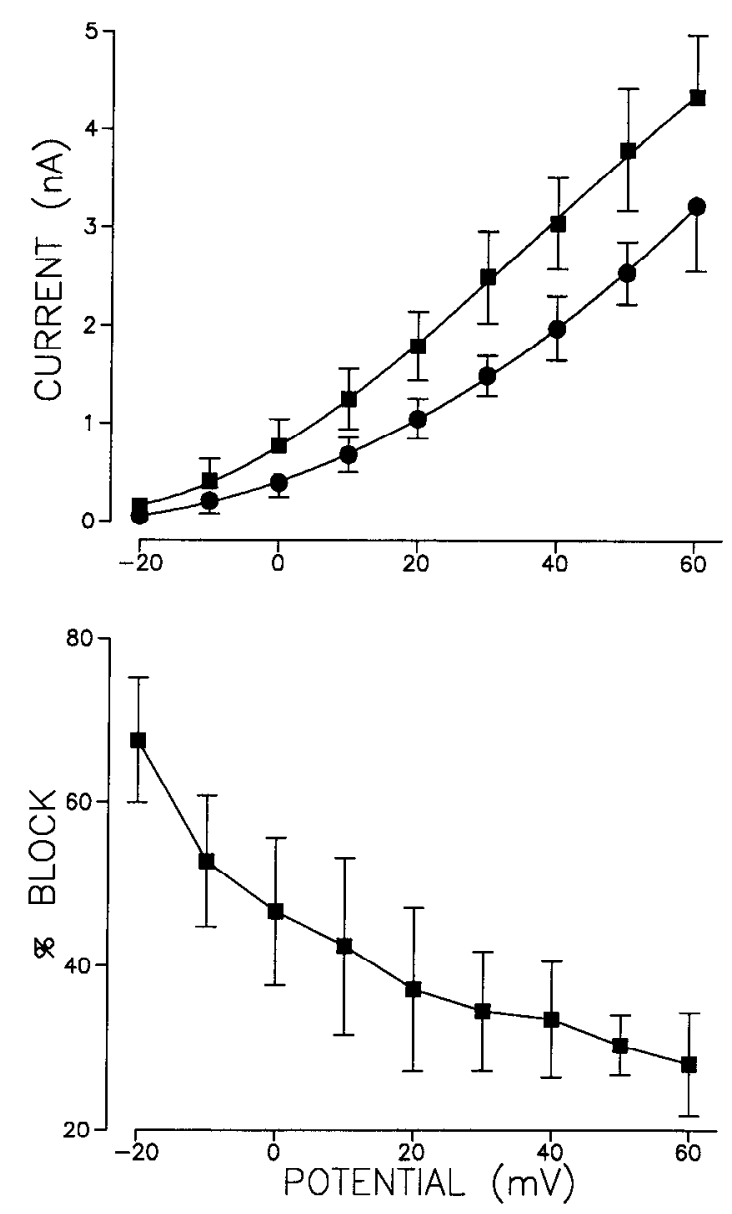

Figure 4. Voltage dependency for PCP block of $I_{\mathrm{K}}$. Upper panel, Current-voltage relationship for $I_{\mathrm{K}}$ under control conditions $(\square)$ and in the presence of PCP $(20 \mu \mathrm{M} ; 0)$. Each point represents the mean \pm SEM of data from 7 cells. Error bars are not shown when they are smaller than the size of the symbols. Lower panel, Percent block was determined as described in Materials and Methods. The mean values were significantly different $(p<0.02)$ by a 1 -way analysis of variance. 
Figure 5. Analysis of the voltage dependency of block according to the method of Woodhull (1973). $A$, Data similar to that shown in Figure 4 were transformed as described in the text using Eq. (3). The straight lines were drawn by a linear least-squares method. The derived parameters are shown. $B$, Analysis of additional data ( 30 cells) as described in the text using Eq. (4).
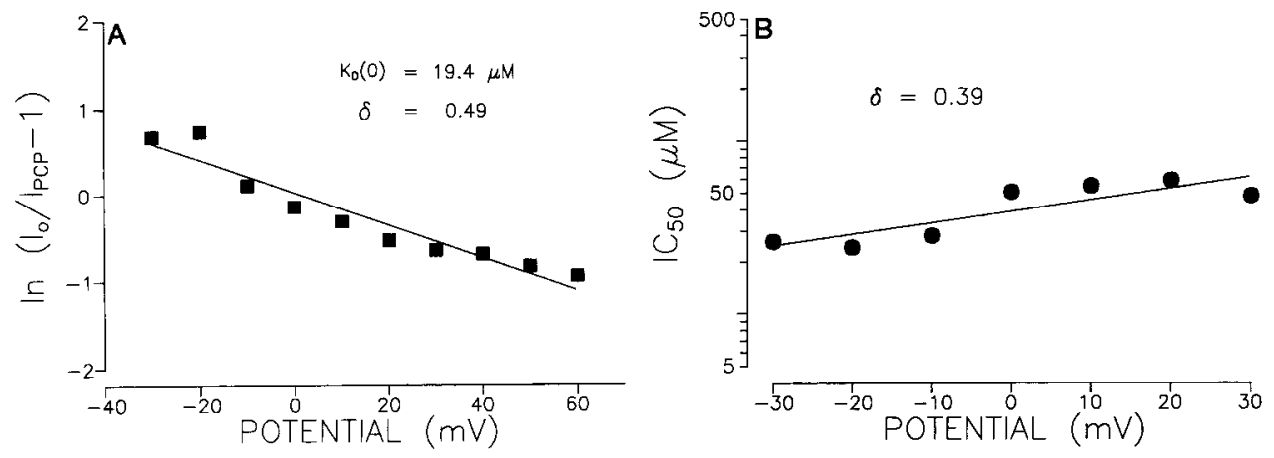

1980; Shapiro, 1977; Armstrong and Croop, 1982) and can be explained by a model in which the blocking drug is able to enter the channel only after it has been opened by depolarization. Alternatively, however, the drug could alter the inactivation characteristics of the $I_{\mathrm{A}}$ channel. To distinguish among these possible mechanisms, we further investigated the onset and recovery of the PCP block.

\section{Block of $\mathbf{I}_{A}$ by high concentrations of PCP is use dependent}

$I_{\mathrm{A}}$ was repetitively activated by brief $(5-6 \mathrm{msec})$ depolarizing steps so that the A-current channels remained in the open state for only a short period of time during each step. The duration of these steps was sufficiently long to include the peak and the inital decay of the A current, but the inactivation period was markedly truncated. In 2 cells tested with this protocol, block occurred in a cumulative (use-dependent) fashion. This is illustrated in Figure 7, which shows the use-dependent reduction of the theoretical current amplitude (assuming maximum activation and no inactivation) estimated from exponential fits to the decay curve extrapolated to zero time. In the presence of PCP, where $I_{\mathrm{A}}$ decayed in 2 exponential phases (see Fig. 7, inset), we used the initial fast phase for the amplitude estimates. The use-dependent reduction in $I_{\mathrm{A}}$ illustrated in Figure 7 supports the concept that high concentrations of PCP block $I_{\mathrm{A}}$ by an open-channel mechanism. Note also in Figure 7 that full recovery from block occurs rapidly after cessation of the PCP superfusion.

\section{$P C P$ has a substantially higher affinity for NMDA-activated cation channels than for voltage-dependent $K^{+}$channels}

It has been well documented that PCP is a potent antagonist of inward current responses evoked by activation of NMDA-type excitatory amino acid receptor-coupled cation channels (Anis et al., 1983; Honey et al., 1985; Lacy and Henderson, 1986; Rothman, 1988). Moreover, it has been argued that PCP (and related drugs such as ketamine and MK-801) bind to an acceptor site within the ionophore of the NMDA receptor that is accessible only when the channel is in the agonist-activated state (Honey et al., 1985; MacDonald et al., 1987; Huettner and Bean, 1988; Mayer et al., 1988). To compare the affinities of the PCP acceptor site associated with the NMDA receptor channel with that of voltage-dependent $\mathrm{K}^{+}$channels, we examined the ability of PCP to block NMDA responses in hippocampal neurons under the same recording conditions as used for the studies of $\mathrm{K}^{+}$channel blockade, except that $\mathrm{Mg}^{2+}$, which itsclf blocks the channel (Mayer et al., 1984; Nowak et al., 1984), was eliminated from the external medium. Inward current responses were evoked by brief $(100 \mathrm{msec})$ pulses of NMDA $(100 \mu \mathrm{M})$. As illustrated in Figure 8, PCP caused a reversible blockade of the responses to NMDA. The dose-effect relationship for concentrations of PCP from $0.1-5 \mu \mathrm{M}$ is shown in Figure $3 A$. The best fit to the data using Eq. (1') gives an $\mathrm{IC}_{50}$ of $0.45 \pm 0.08 \mu \mathrm{M}$. Since $n=$ $1.1 \pm 0.2$, the data suggest the existence of a single binding site on the NMDA channel and the $\mathrm{IC}_{50}$ can be interpreted as the dissociation constant $\left(K_{D}\right)$ of this site.
Figure 6. Effect of PCP on $I_{\mathrm{K}}$ activation kinetics and $I_{\mathrm{A}}$ inactivation kinetics. $A, I_{\mathrm{K}}$ was elicited by step depolarization from -40 to $+30 \mathrm{mV}$. Currents recorded before and during superfusion with $20 \mu \mathrm{M}$ PCP were normalized to the peak current during the step (control: $1.7 \mathrm{nA}$; PCP: $1.0 \mathrm{nA}$ ). Straight lines give the best fits to the 2 exponential phases of the control data as determined by the method of peeling. $B, I_{\mathrm{A}}$ was elicited by step depolarization to $+30 \mathrm{mV}$ after a $200 \mathrm{msec}$ prepulse to $-90 \mathrm{mV}$. Currents recorded before and during superfusion with $500 \mu \mathrm{M}$ PCP (less the steady-state current at the end of the $200 \mathrm{msec}$ step) were normalized to the peak currents (control: $2.4 \mathrm{nA}$ at $7.5 \mathrm{msec}$; PCP: $1.7 \mathrm{nA}$ at $3.5 \mathrm{msec}$ ). Best-fit lines were determined as in $A$. Same cell as Figure $2 B$.
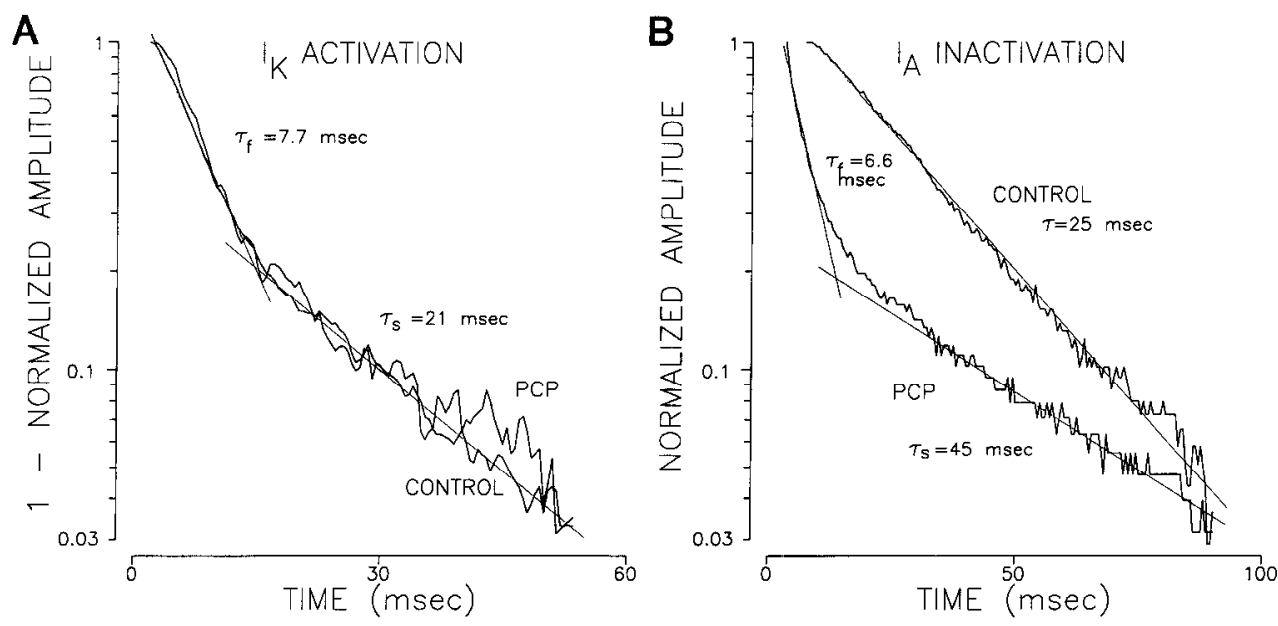


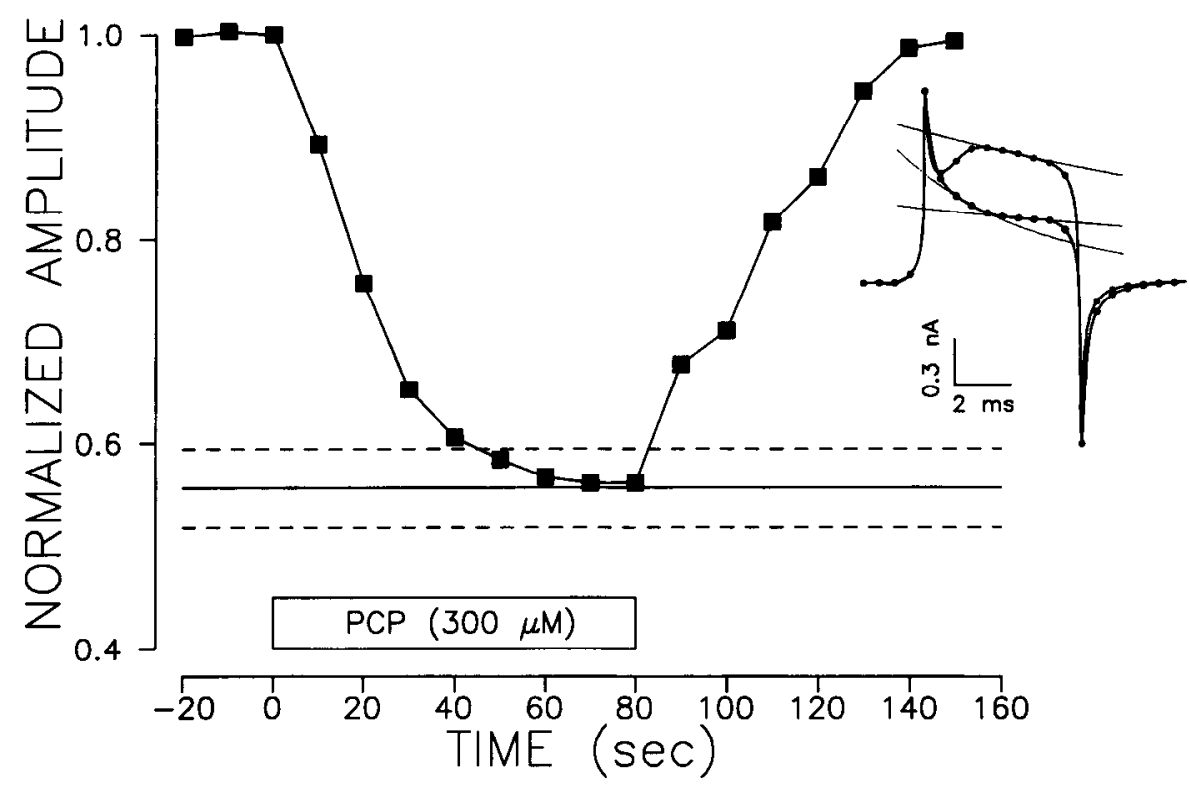

Figure 7. Use-dependent block of $I_{\mathrm{A}} \cdot I_{\mathrm{A}}$ was repetitively evoked at $10 \mathrm{sec}$ intervals with $6 \mathrm{msec}$ duration depolarizing steps to $+30 \mathrm{mV}$ after a $200 \mathrm{msec}$ prepulse to $-90 \mathrm{mV}$. The step protocol was applied before, during (indicated by open bar) and after superfusion with PCP (300 $\mu \mathrm{M}$ ). Between steps, the cell was held at $-60 \mathrm{mV}$. TEA $(20 \mathrm{~mm})$ was present in the bathing medium to reduce $I_{\mathrm{K}}$. The control $I_{\mathrm{A}}$ theoretical maximal amplitude was estimated from exponential fits to the decay curve ex(rapolated to zero time (see inset). During PCP, the decay occurred in 2 exponential phases; the initial fast phase was used for the amplitude determinations. For each step, the $I_{\mathrm{A}}$ amplitude, normalized to the value at zero time (1.02 $\mathrm{nA}$ ), is plotted against the time before (negative time values) or after the onset of the PCP superfusion. The solid horizontal line represents the steady-state block obtained with several long $(200 \mathrm{msec})$ steps (same data as in Fig. 3); the dashed horizontal lines represent the SEM. Inset, Control current trace and the current trace $20 \mathrm{sec}$ after onset of the PCP superfusion. The thin smooth curves show the exponential fits. Note that the current trace recorded during PCP is fit with 2 exponentials (see Fig. 6). Capacitance transients have not been subtracted.

We also evaluated the ability of the dioxadrol enantiomers dexoxadrol and levoxadrol to block NMDA-induced inward current. Dioxadrol is a chiral dioxolane analog whose dextrorotatory form, dexoxadrol, has pharmacological characteristics similar to PCP, whereas its levorotatory form, levoxadrol, is virtually devoid of PCP-like activity (see Discussion). As expected, dexoxadrol $(10 \mu \mathrm{M})$ was a potent antagonist of NMDA responses, whereas levoxadrol at the same concentration was inactive (Table 1).

\section{Dioxadrol enantiomers block $\mathrm{I}_{K}$ in a stereoselective fashion}

Figures $9 A-D$ compare the activity of the dioxadrol stereoisomers with that of PCP as blockers of $I_{\mathrm{K}}$. At $100 \mu \mathrm{M}$, dexoxadrol causes a substantial block of $I_{\mathrm{K}}(53 \%$; Fig. $9 \mathrm{C})$, although the degree of block is less than that produced by PCP at the same concentration (77\%; Fig. $9 B$ ). In contrast, levoxadrol is less potent in blocking $I_{\mathrm{K}}(14 \%$; Fig. $9 D)$. Dose-effect curves for dexoxadrol and levoxadrol blockade of $I_{\mathrm{K}}$ and $I_{\mathrm{A}}$ are shown in Figure $10 \mathrm{~A}$. As is the case with $\mathrm{PCP}$, dexoxadrol is a more potent blocker of $I_{\mathrm{K}}$ than of $I_{\mathrm{A}}$. The dose-effect curves further illustrate the enantioselectivity of the $I_{\mathrm{K}}$ blockade; however, there is no such stereoselectivity for blockade of $I_{\mathrm{A}}$.

\section{$\mathrm{K}^{+}$channel blockade does not occur via sigma sites}

To further characterize the pharmacological properties of the PCP-acceptor site on the voltage-dependent $\mathrm{K}^{+}$channels of hippocampal neurons, we examined the channel blocking potencies of several sigma site ligands. The sigma site was originally defined on the basis of the binding of the prototypical benzomorphan (+)-SKF $10,047[(+)-N$-allylnormetazocine] to brain membranes (Mendelsohn et al., 1985; Sircar et al., 1986). More recently, however, drugs such as (+)-3-(3-hydroxyphenyl)- $N$ (1-propyl)piperidine [(+)-3-PPP] have been discovered which bind with higher selectivity to the site (Largent et al., 1986,

\section{CONTROL}

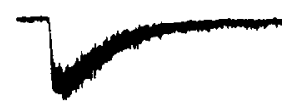

NMDA $(100 \mu \mathrm{M})$

1
PCP

$(1 \mu \mathrm{M})$

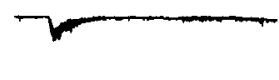

RECOVERY
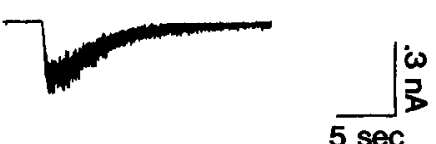

Figure 8. PCP-induced depression (68\%) of inward current responses evoked by NMDA (100 $\mu \mathrm{M} ; 100 \mathrm{msec}$ application). NMDA was pulsed at $30 \mathrm{sec}$ intervals during the PCP superfusion until no further decrement in the current was obtained. The record shown was obtained 90 sec following the onset of the superfusion. 

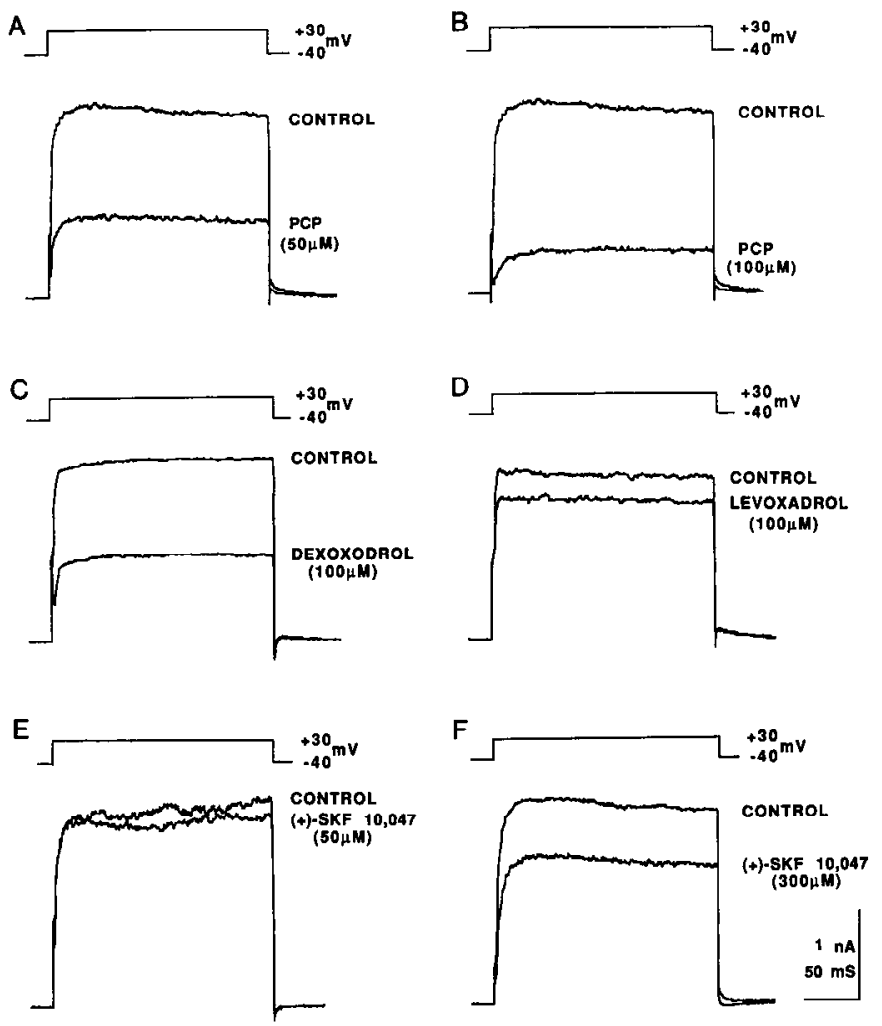

Figure 9. Comparison of the effects of PCP, the dioxadrol enantiomers dexoxadrol and levoxadrol, and (+)-SKF 10,047 on $I_{\mathrm{K}} . A$ and $B$ are from experimetns on the same cell; $C-F$ are from different cells. Percent block of the current at the end of the $200 \mathrm{msec}$ step are as follows: $A$, $58 ; B, 77 ; C, 53 ; D, 8 ; E, 14 ; F, 28$.

1987). PCP has a moderate affinity for sigma binding sites (Largent et al., 1986; Contreras et al., 1988; Itzhak, 1988; Wong et al., 1988), and therefore, the $\mathrm{K}^{+}$channel blocking activity of PCP could result from its interaction with sigma sites. Figurc $9, E, F$, illustrates that (+)-SKF 10,047 is a very weak blocker of $I_{\mathrm{K}}$. This is further demonstrated by the dose-effect curves shown in Figure 10B. Even at concentrations as high as 300$500 \mu \mathrm{M},(+)$-SKF 10,047 and its enantiomer (-)-SKF 10,047 failed to block $I_{\mathrm{K}}$ by $50 \%$, so that an $\mathrm{IC}_{50}$ could not be determined. Similarly, the selective sigma site ligand (+)-3-PPP only partially blocked $I_{\mathrm{K}}$ at doses as high as $300 \mu \mathrm{M}$. Since these drugs are more potent ligands for sigma sites than for PCP sites (Downes et al., 1986; Largent et al., 1986), it can be concluded that PCP does not block $I_{\mathrm{K}}$ channels via an acceptor site that is of the sigma type.

\section{Discussion}

As initially demonstrated by Bartschat and Blaustein (1986) on the basis of $\mathrm{Rb}^{+}$flux measurements in rat brain synaptosomes, our studics confirm that PCP is a potent and selective blocker of voltage-dependent $\mathrm{K}^{+}$channels in rat $\mathrm{CNS}$ neurons. At low concentrations ( $<50-100 \mu \mathrm{M})$, PCP selectively blocks the sustained voltage-dependent $\mathrm{K}^{+}$current $\left(I_{\mathrm{K}}\right)$ channel and only affects the transient $\mathrm{K}^{+}$current $\left(I_{\mathrm{A}}\right)$ channel at higher concentrations. Two previous voltage-clamp studies also reported that PCP can block voltage-dependent $\mathrm{K}^{+}$currents in cultured spinal cord (Aguayo and Alburquerque, 1987) and hippocampal (Rothman, 1988) neurons, yet failed to observe a selective effect
Table 1. Effect of dioxadrol enantiomers on NMDA-evoked inward current responses

\begin{tabular}{lll} 
& Percent block & \\
\cline { 2 - 3 } Test drug & $(5 \mu \mathrm{M})$ & $(10 \mu \mathrm{M})$ \\
\hline Dexoxadrol & $3.6 \pm 3.5$ & $76.0 \pm 5.6$ \\
& $(4)$ & $(6)$ \\
Levoxadrol & 0 & 0 \\
& $(3)$ & $(4)$
\end{tabular}

Inward current responses were elicited with $100 \mathrm{msec}$ pressure pulses of NMDA $(100 \mu \mathrm{M})$. The percent block was calculated as described in Materials and Methods 2-3 min after onset of the drug superfusion. The holding potential was $-60 \mathrm{mV}$. The number of cells tested at each dose is shown in parentheses. Data are presented as the mean $\pm \mathrm{SEM}$.

on $I_{\mathrm{K}}$. However, in these studies PCP concentrations of $100 \mu \mathrm{M}$ or more were used, and at these concentrations we also found that the drug depresses both $I_{\mathrm{K}}$ and $I_{\mathrm{A}}$.

In addition to confirming that PCP blocks $I_{\mathrm{K}}$ and $I_{\mathrm{A}}$ channels with different potencies, the present study also suggests that the precise way in which PCP interacts with the 2 channel types may differ. PCP blocks $I_{\mathrm{K}}$ channels by binding to a site with a $K_{D}$ of $26 \mu \mathrm{M}$. The voltage dependency of the PCP block indicates that the PCP acceptor site senses about $40-50 \%$ of the transmembrane electric field. It is likely that the acceptor site is within the channel pore. However, other interpretations of these data are possible. For example, the acceptor site could theoretically be outside the transmembrane electrostatic field if a membrane potential-dependent conformational change altered its binding affinity or it could inhibit ion transit through the channel by binding to an allosteric site within the electrostatic field but outside the pore per se. Block of $I_{\mathrm{K}}$ occurs more rapidly than the current activates and does not show use dependency. In addition, $I_{\mathrm{K}}$ channels recover from block even in the absence of voltage-dependent activation (unpublished observations), indicating that PCP is not trapped within the closed channel. These results suggest that block may occur through a hydrophobic pathway in which the drug is able to bind to closed channels (see Hille, 1977). Nevertheless, the possibility cannot be excluded that binding and unbinding are so rapid that neither pseudoinactivation nor use dependency is observed, despite an open channel-blocking mechanism.

In contrast to the results with $I_{\mathrm{K}}$, PCP only weakly blocked $I_{\mathrm{A}}$, but at high concentrations that caused a substantial reduction in the current there was a marked speeding of the decay rate. In addition, with repeated brief voltage steps, we observed cumulative block of the current which rapidly recovered upon cessation of the drug superfusion. These observations indicate that PCP block of $I_{\mathrm{A}}$ is use dependent and suggest that $I_{\mathrm{A}}$ channels must open before they can become blocked, so that block occurs via a hydrophilic pathway.

The mechanism by which PCP blocks $I_{\mathrm{K}}$ channels may also differ from the way in which PCP-related drugs interact with NMDA receptor channels. As discussed above, there is substantial evidence in favor of the concept that NMDA receptor channels must be in the agonist activated state for binding and block to occur. Moreover, the drug molecule can become trapped within the ionophore when the channels close so that they are only liberated upon reopening (MacDonald et al., 1987; Huettner and Bean, 1988). Thus, block of the NMDA receptor channel occurs via a hydrophilic mechanism like the block of $I_{\mathrm{A}}$. 

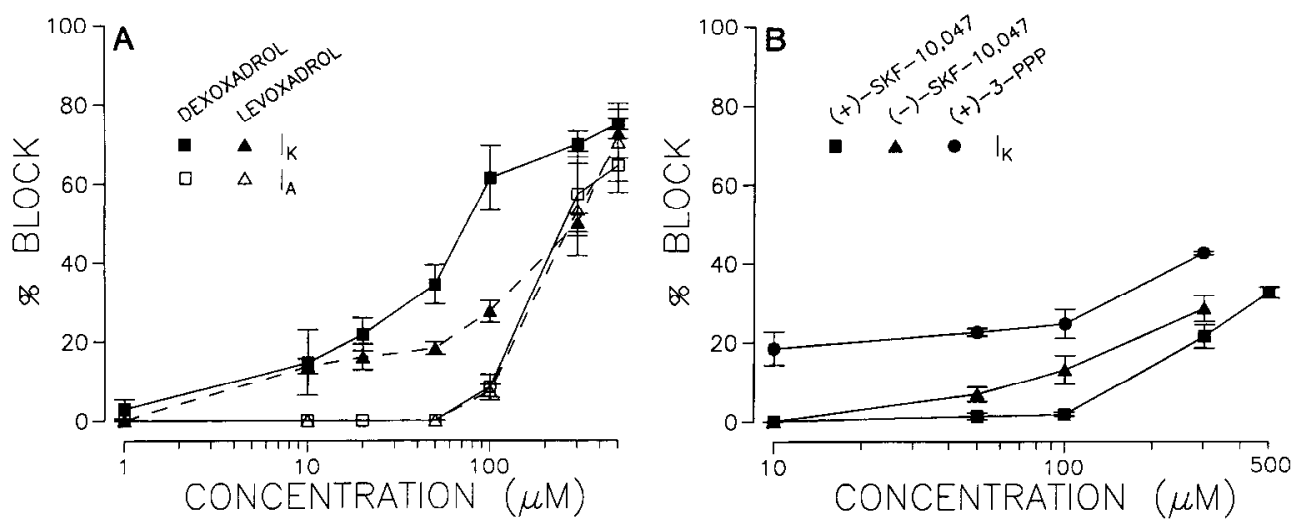

Figure 10. Dose-effect curves for block of $I_{\mathrm{K}}$ and $I_{\mathrm{A}}$ by $(A)$ dioxadrol enantiomers dexoxadrol and levoxadrol, and $(B)(+)$ - and $(-)-\mathrm{SKF} 10,047$, and (+)-3-PPP. The experimental protocol and method of data analysis are the same as in Figure 7. IC ${ }_{50}$ values in $A$ are as follows $(\mu \mathrm{M})$ : dexoxadrol $I_{\mathrm{K}}, 73$; dexoxadrol $I_{\mathrm{A}}, 260$; levoxadrol $I_{\mathrm{K}}, 285$, levoxadrol $I_{\mathrm{A}}, 285$. $\mathrm{IC}_{50}$ values for drugs shown in $B$ are $>300-500 \mu \mathrm{M}$. Each point represents the mean \pm SEM of experiments with $4-5$ cells.

Studies with ${ }^{3} \mathrm{H}-\mathrm{PCP}$ and related radioligands have demonstrated the existence of high-affinity binding sites in brain membranes with a pharmacological profile for PCP-related drugs that corresponds with the behavioral activity of the drugs in inducing PCP-like behaviors (Vincent et al., 1979; Zukin and Zukin, 1979). These binding sites are present in high density in the rat hippocampus (Quirion et al., 1981; Largent et al., 1986). Recently, it was proposed that these binding sites represent the ionophore of the NMDA receptor channel (Fagg, 1987; Bonhaus and McNamara, 1988; Kloog et al., 1988; Wong et al., 1988). Moreover, although PCP does bind to sigma sites with moderate affinity, sigma-selective drugs such as (+)-3-PPP bind only very weakly to high-affinity PCP sites (Downes et al., 1986; Largent et al., 1986), indicating that PCP and sigma sites are pharmacologically distinct. Physiological studies in the hippocampal slice have demonstrated that PCP's block of excitatory transmission is probably not mediated by sigma sites (Coan and Collingridge, 1987; Malouf et al., 1988). [Although Coan and Collingridge reported that $( \pm)$-SKF 10,047 did block excitation, there was no difference in the potencies of the enantiomers, suggesting that the effect was mediated by the PCP-like activity of the drugs since PCP binding sites show less selectivity for the SKF 10,047 enantiomers than do sigma sites (Largent et al., 1986; Contreras et al., 1988; Sokolovsky and Kloog, 1988).] As is the case with the NMDA receptor channel, we have demonstrated that PCP's interaction with voltage-dependent $\mathrm{K}^{+}$ channels does not occur via its sigma binding activity. However, are there pharmacological differences between the PCP binding site on the NMDA receptor channel and the site on $\mathrm{K}^{+}$channels? Clearly, PCP binds with greater affinity to the NMDA receptor channel. This is true even if the affinity for the $I_{\mathrm{K}}$ channel is corrected to $-60 \mathrm{mV}$ (where the block of the NMDA-activated current was determined) using Eq. (4). In this case, the theoretical $K_{D}(-60 \mathrm{mV})$ for blockade of $I_{\mathrm{K}}$ would be $\sim 6 \mu \mathrm{M}$, an order of magnitude greater than the $K_{D}(-60 \mathrm{mV})$ for blockade of the NMDA receptor channel $(0.45 \mu \mathrm{M})$. Moreover, the enantioselectivity of NMDA receptor channels for the dioxadrol stereoisomers may be greater than the stereoselectivity we have observed for $I_{\mathrm{K}}$ channels. In radioligand binding studies using PCP-related ligands, dexoxadrol has a 230- to 412-fold greater binding affinity than levoxadrol (Mendelsohn et al., 1984, 1985; Contreras et al., 1986; Largent et al., 1986; Fagg, 1987). Functional studies have demonstrated that levoxadrol is inactive in blocking NMDA responses (Berry et al., 1984; Coan and Collingridge, 1987; Jones et al., 1987; Bourne et al., 1988; Kushner et al., 1988) and in inducing PCP-like behavioral effects (Snell and Johnson, 1985; Contreras et al., 1986). Our data (Table 1) confirm that dexoxadrol has far greater activity as an NMDA antagonist than does levoxadrol. In contrast, there was only a 4-fold difference between dexoxadrol and levodadrol in their $\mathrm{IC}_{50}$ values for blockade of $I_{\mathrm{K}}$. These considerations indicate that the pharmacological specificities of the PCP site on the NMDA receptor channel and that on the $I_{\mathrm{K}}$ channel may differ, and, furthermore, suggest that the $\mathrm{K}^{+}$channel may not represent the behaviorally relevant site of PCP action. However, blockade of voltage-dependent $\mathrm{K}^{+}$channels may be important in mediating some of the pharmacological actions of PCP, such as its propensity to induce convulsions at high doses (Domino et al., 1983; Leccese et al., 1986).

Recently, Bartschat and Blaustein (1988) have reported the effects of dioxadrol stereoisomers and sigma ligands on sustained voltage-dependent $\mathrm{K}^{+}$channels in rat brain synaptosomes as determined by measurements of ${ }^{86} \mathrm{Rb}^{+}$efflux. While in general terms the results obtained with this technique are comparable to those we have obtained in the present electrophysiological study (see Bartschat and Blaustein, 1986), this more recent study has revealed some differences in the pharmacological properties of the channels as studied by the 2 techniques. In particular, Bartschat and Blaustein (1988) observed a greater potency difference between dexoxadrol and levoxadrol than was found in the present study, and, in addition, these workers reported that (+)-SKF 10,047 was significantly more potent than PCP in blocking the channels. The reason for the differences in the results obtained with the 2 methods is unclear. However, inasmuch as the pharmacological profile obtained in the flux studies does not correspond with either PCP [dexoxadrol $>$ levoxadrol; PCP $>(+)$-SKF 10,047] or sigma [dexoxadrol $\approx$ levoxadrol, both weak; (+)-SKF 10,047 > PCP] typc binding sites, the nature of the pharmacophore detected with this methodology requires further clarification.

In conclusion, while it is apparent that PCP can block a wide variety of different ion channel species, the present study demonstrates that the details of the interaction may differ substantially depending upon the specific channel type. In all cases which have been examined in sufficient detail, ion channel block by PCP appears to occur via binding of the drug molecule to a 
site within the ionophore. However, the affinity of this interaction differs among channel types, as does the requirement for channel opening and the tendency of drug molecules to become trapped within closed channels. These variations in blocking mechanism can be expected to contribute to the complex pharmacological profile of PCP.

\section{References}

Adams, P. R. (1976) Drug blockade of open end-plate channels. J. Physiol. (Lond.) 260: 531-552.

Aguayo, L. G., and E. X. Albuquerque (1986) Effects of phencyclidine and its analogs on the end-plate current of the neuromuscular junction. J. Pharmacol. Exp. Ther. 239: 15-24.

Aguayo, L. G., and E. X. Albuquerque (1987) Phencyclidine blocks two potassium currents in spinal neurons in cell culture. Brain Res. 436: 9-11.

Albuquerque, E. X., L. G. Aguayo, J. E. Warnick, H. Weinstein, S. D. Glick, S. Maayani, R. K. Ickowicz, and M. P. Blaustein (1981) The behavioral effects of phencyclidines may be due to their blockade of potassium channels. Proc. Natl. Acad. Sci. USA 78: 7792-7796.

Anis, N. A., S. C. Berry, N. R. Burton, and D. Lodge (1983) The dissociative anaesthetics, ketamine and phencyclidine, selectively reduce excitation of central mammalian neurones by $N$-methyl-D-aspartate. Br. J. Pharmacol. 79: 565-575.

Armstrong, C. M., and R. S. Croop (1982) Simulation of Na channel inactivation by thiazin dyes. J. Gen. Physiol. 80: 641-662.

Bartschat, D. K., and M. P. Blaustein (1986) Phencyclidine in low doses selectively blocks a presynaptic voltage-regulated potassium channel in rat brain. Proc. Natl. Acad. Sci. USA 83: 189-192.

Bartschat, D. K., and M. P. Blaustein (1988) Psychotomimetic $\sigma$-ligands, dexoxadrol and phencyclidine block the same presynaptic potassium channel in rat brain. J. Physiol. (Lond.) 403: 341-353.

Berry, S. C., N. A. Anis, and D. Lodge (1984) The effect of the dioxolanes on amino acid induced excitation in the mammalian spinal cord. Brain Res. 307: 85-90.

Blatz, A. L., and K. L. Magleby (1984) Ion conductance and selectivity of single calcium-activated potassium channels in cultured rat muscle. J. Gen. Physiol. 84: 1-23.

Bonhaus, D. W., and J. O. McNamara (1988) $N$-Methyl-D-aspartate receptor regulation of uncompetitive antagonist binding in rat brain membranes: Kinctic analysis. Mol. Pharmacol. 34: 250-255.

Bourne, G. W., B. Esplin, and R. Capek (1988) Disinhibitory effect of phencyclidine in the hippocampus in vitro: $\mathrm{PCP}$ receptors implicated. Eur. J. Pharmacol. 150:67-74.

Cahalan, M. D., and W. Almers (1979) Block of sodium conductance and gating current in squid giant axons poisoned with quaternary strychnine. Biophys. J. 27: 57-74.

Choi, D. W., and G. D. Fischbach (1981) GABA conductance of chick spinal cord and dorsal root ganglion neurons in cell culture. J. Neurophysiol. 45: 605-620.

Coan, E. J., and G. L. Collingridge (1987) Effects of phencyclidine, SKF 10,047 and related psychotomimetic agents on $N$-methyl-Daspartate receptor mediated synaptic responses in rat hippocampal slices. Br. J. Pharmacol. 91: 547-556.

Contrcras, P. C., K. C. Rice, A. E. Jacobson, and T. L. O'Donohue (1986) Stereotyped behavior correlates better than ataxia with phencyclidine-receptor interactions. Eur. J. Pharmacol. 121: 9-18.

Contreras, P. C., M. L. Contreras, T. L. O'Donohue, and C. C. Lair (1988) Biochemical and behavioral effects of sigma and PCP ligands. Synapse 2: 240-243.

Coronado, R., and C. Miller (1979) Voltage-dependent caesium blockade of a cation channel from fragmented sarcoplasmic reticulum. Nature 280: 807-810.

De Lean, A., P. J. Munson, and D. Rodbard (1978) Simultaneous analysis of families of sigmoidal curves: Application to bioassay, radioligand assay, and physiological dose-response curves. Am. J. Physiol. 235: E97-E102.

Domino, E. F., N. Fukuda, and A. Simonic (1983) Comparative electroencephalographic and gross behavioral effects of phencyclidine, related substances and various centrally acting drugs in Macaca mulatta. In Phencyclidine and Related Arylcyclohexylamines: Present and Future Applications, J. M. Kamenka, E. F. Domino, and P. Geneste, eds., pp. 369-395, NPP Books, Ann Arbor, MI.
Downes, C. P., P. E. Lewis, and M. A. Stone (1986) A comparison of the binding of $\sigma$ opioids and phencyclidine, and the interaction with antipsychotic drugs in rat brain membranes. Br. J. Pharmacol. 88: 231-237.

Fagg, G. E. (1987) Phencyclidine and related drugs bind to the activated $N$-methyl-D-aspartate receptor-channel complex in rat brain membranes. Neurosci. Lett. 76: 221-227.

ffrench-Mullen, J. M. H., M. A. Rogawski, and J. L. Barker (1988) Phencyclidine at low concentrations selectively blocks the sustained but not the transient voltage-dependent potassium current in cultured hippocampal neurons. Neurosci. Lett. 88: 325-330.

Hadley, R. W., and J. R. Hume (1986) Actions of phencyclidine on the action potential and membrane currents of single guinea-pig myocytes. J. Pharmacol. Exp. Ther. 237: 131-136.

Hillc, B. (1977) Local anesthetics: Hydrophilic and hydrophobic pathways for the drug-receptor reaction. J. Gen. Physiol. 69: 497-515.

Honey, C. R., Z. Miljkovic, and J. F. MacDonald (1985) Ketamine and phencyclidine cause a voltage-dependent block of responses to L-aspartic acid. Neurosci. Lett. 61: 135-139.

Huettner, J. E., and B. P. Bean (1988) Block of $N$-methyl-D-aspartateactivated current by the anticonvulsant MK-801: Selective binding to open channels. Proc. Natl. Acad. Sci. USA 85: 1307-1311.

Itzhak, Y. (1988) Pharmacological specificity of some psychotomimetic and antipsychotic agents for sigma and PCP binding sites. Life Sci. 42: 745-752.

Jones, S. M., L. D. Snell, and K. M. Johnson (1987) Phencyclidine selectively inhibits $N$-methyl-D-aspartate-induced hippocampal $\left[{ }^{3} \mathrm{H}\right]$ norepinephrine release. J. Pharmacol. Exp. Ther. 240: 492-497.

Kirsch, G. E., J. Z. Ych, J. M. Farlcy, and T. Narahashi (1980) Interaction of $n$-alkylguanidines with sodium channels of squid axon membrane. J. Gen. Physiol. 76: 315-335.

Kloog, Y., R. Haring, and M. Sokolovsky (1988) Kinetic characterization of the phencyclidine- $N$-methyl-D-aspartate receptor interaction: Evidence for a steric blockade of the channel. Biochemistry 27: 843-848.

Kushner, L., J. Lerma, R. S. Zukin, and M. V. L. Bennett (1988) Coexpression of $N$-methyl-D-aspartate and phencyclidine receptors in Xenopus oocytes injected with rat brain mRNA. Proc. Natl. Acad. Sci. USA 85: 3250-3254.

Lacey, M. G., and G. Henderson (1986) Actions of phencyclidine on rat locus coeruleus neurones in vitro. Neuroscience 17: 485-494.

Largent, B. L., A. L. Gundlach, and S. H. Snyder (1986) Pharmacological and autoradiographic discrimination of sigma and phencyclidine receptor binding sites in brain with $(+)-\left[{ }^{3} \mathrm{H}\right] \mathrm{SKF} 10,047,(+)-$ $\left[{ }^{3} \mathrm{H}\right]-3$-[hydroxyphenyl]- $N$-(1-propyl)piperidine and $\left[{ }^{3} \mathrm{H}\right]-1-[1-(2-$ thienyl)-cyclohexyl]piperidine. J. Pharmacol. Exp. Ther. 238: 739748.

Largent, B. L., H. Wikström, A. L. Gundlach, and S. H. Snyder (1987) Structural determinants of $\sigma$ receptor aftinity. Mol. Pharmacol. 32: 772-784.

Leccese, A. P., K. L. Marquis, A. Mattia, and J. E. Moreton (1986) The convulsant and anticonvulsant effects of phencyclidine (PCP) and PCP analogues in the rat. Behav. Brain Res. 19: 163-169.

Maayani, S., M. R. Rosenfeld, and B. Pazhenchevsky (1983) Partition coefficient and $\mathrm{pK}_{\mathrm{a}}$ values for PCP analogs. In Phencyclidine and Related Arylcyclohexylamines: Present and Future Applications, J. M. Kamenka, E. F. Domino, and P. Geneste, eds., pp. 71-81, NPP Books, Ann Arbor, MI

MacDonald, J. F., Z. Miljkovic, and P. Pennefather (1987) Use-dependent block of excitatory amino acid currents in cultured neurons by ketamine. J. Neurophysiol. 58: 251-266.

Malouf, A. T., E. Swearengen, and C. Chavkin (1988) Comparison of the actions of phencyclidine and sigma ligands on CAl hippocampal pyramidal neurons in the rat. Neuropharmacology 27: 1161-1170.

Mayer, M. L., G. L. Westbrook, and P. B. Guthrie (1984) Voltagedependent block by $\mathrm{Mg}^{2+}$ of NMDA responses in spinal cord neurones. Nature 309: 261-263.

Mayer, M. I., G. I. Westbrook, and L. Vyklicky, Jr. (1988) Sites of antagonist action on $N$-methyl-D-aspartic acid receptors studied using fluctuation analysis and a rapid perfusion technique. J. Neurophysiol. 60: 645-663.

Mendelsohn, L. G., G. A. Kerchner, V. Kalra, D. M. Zimmerman, and J. D. Leander (1984) Phencyclidine receptors in rat brain cortex. Biochem. Pharmacol. 33: 3529-3535.

Mendelsohn, L. G., V. Kalra, B. G. Johnson, and G. A. Kerchner (1985) 
Sigma opioid receptor: Characterization and co-identity with the phencyclidine receptor. J. Pharmacol. Exp. Ther. 233: 597-602.

Nowak, L., P. Bregestovski, P. Ascher, A. Herbet, and A. Prochiantz (1984) Magnesium gates glutamate-activated channels in mouse central neurones. Nature 307: 462-465.

Oswald, R. E., M. J. Bamberger, and J. T. McLaughlin (1984) Mechanism of phencyclidine binding to the acetylcholine receptor from Torpedo electroplaque. Mol. Pharmacol. 25: 360-368.

Quirion, R., R. P. Hammer, Jr., M. Herkenham, and C. B. Pert (1981) Phencyclidine (angel dust) $/ \sigma$ "opiate" receptor: Visualization by tritium-sensitive film. Proc. Natl. Acad. Sci. USA 78: 5881-5885.

Rogawski, M. A., M. Pieniek, S. Suzuki, and J. M. H. ffrench-Mullen (1988) Phencyclidine selectively blocks the sustained voltage-dependent potassium conductance in PC12 cells. Brain Res. 456: 38-48.

Rothman, S. (1988) Noncompetitive $N$-methyl-D-aspartate antagonists affect multiple ionic currents. J. Pharmacol. Exp. Ther. 246: 137-142.

Segal, M. (1983) Rat hippocampal neurons in culture: Responses to electrical and chemical stimuli. J. Neurophysiol. 50: 1249-1264.

Segal, M., and J. L. Barker (1984) Rat hippocampal neurons in culture: Potassium conductances. J. Neurophysiol. 51: 1409-1433.

Segal, M., M. A. Rogawski, and J. L. Barker (1984) A transient potassium conductance depresses the excitability of cultured rat hippocampal and spinal neurons. J. Neurosci. 4: 604-609.

Shapiro, B. I. (1977) Effects of strychnine on the sodium conductance of the frog node of ranvier. J. Gen. Physiol. 69: 915-926.

Sircar, R., R. Nichtenhauser, J. R. Ieni, and S. R. Zukin (1986) Characterization and autoradiographic visualization of $(+)-\left[{ }^{3} \mathrm{H}\right] \mathrm{SKF} 10047$ binding in rat and mouse brain: Further evidence for phencyclidine/ "sigma opiate" receptor commonality. J. Pharmacol. Exp. Ther. 237: 681-688.

Smart, T. G. (1987) Single calcium-activated potassium channels recorded from cultured rat sympathetic neurones. J. Physiol. (Lond.) 389: 337-360.
Snell, L. D., and K. M. Johnson (1985) Antagonism of $N$-methyl-Daspartate-induced transmitter release in the rat striatum by phencyclidine-like drugs and its relationship to turning behavior. J. Pharmacol. Exp. Ther. 235: 50-57.

Sokolovsky, M., and Y. Kloog (1988) Solubilization and biochemical characterization of PCP and MK-801 binding sites in rat brain: Evidence for a steric blockade of NMDA-channel. In Frontiers in Excitatory Amino Acid Research, E. A. Cavalheiro, J. Lehmann, and L. Turski, eds., pp. 13-20, Liss, New York

Tallarida, R. J., and R. B. Murray (1987) Manual of Pharmacologic Calculations with Computer Programs, Springer-Verlag, New York.

Tourneur, Y., G. Romey, and M. Lazdunski (1982) Phencyclidine blockade of sodium and potassium channels in neuroblastoma cells. Brain Res. 245: 154-158.

Vincent, J. P., B. Kartalovski, P. Geneste, J. M. Kamenka, and M. Lazdunski (1979) Interaction of phencyclidine ("angel dust") with a specific receptor in rat brain membranes. Proc. Natl. Acad. Sci. USA 76: 4678-4682.

Woodhull, A. M. (1973) Ionic blockage of sodium channels in nerve. J. Gen. Physiol. 61: 687-708.

Wong, B. S., and M. Adler (1986) Tetraethylammonium blockade of calcium-activated potassium channels in clonal anterior pituitary cells. Pfluegers Arch. 407: 279-284.

Wong, E. H. F., A. R. Knight, and G. N. Woodruff (1988) [ ${ }^{3}$ H]MK801 labels a site on the $N$-methyl-D-aspartate receptor channel complex in rat brain membranes. J. Neurochem. 50: 274-281.

Yeh, J. Z., and T. Narahashi (1977) Kinetic analysis of pancuronium interaction with sodium channels in squid axon membrancs. J. Gen. Physiol. 69: 293-323.

Zukin, S. R., and R. S. Zukin (1979) Specific [ $\left.{ }^{3} \mathrm{H}\right]$ phencyclidine binding in rat central nervous system. Proc. Natl. Acad. Sci. USA 76: 53725376. 